\title{
RETRACTION
}

DOI: $10.3892 / \mathrm{ol} .2020 .12063$

\section{Scorpion venoms in gastric cancer (Review)}

\section{XIAO-YING ZHANG and PEI-YING ZHANG}

Oncol Lett 12: 3683-3686, 2016; DOI: 10.3892/ol.2016.5134

Following the publication of this article, an interested reader drew to our attention that the flow of the text, and the wording of numerous passages of text within the article, bore striking and unexpected similarities to the wording employed in a $\mathrm{PhD}$ thesis by Ding Jian at the National University of Singapore in 2014 entitled "Screening and Evaluation of the Anticancer Potential of Scorpion Venoms and Snake Venom L-Amino Acid Oxidase in Gastric Cancer".

After having conducted an internal investigation, the Editor of Oncology Letters has determined beyond all reasonable doubt that the review submitted to the Journal shared an unacceptable level of identity with the $\mathrm{PhD}$ thesis by Ding Jian. The authors were contacted about these apparent similarities between their review and the thesis, and they agree to this retraction. The Editor of Oncology Letters deeply regrets that this article was not intercepted by our own checks for plagiarism prior to the publication of the review, and sincerely apologizes to the author of the $\mathrm{PhD}$ thesis and the readership for the inconvenience caused. We also thank the reader for bringing this matter to our attention. 